\title{
Coffee: The Driver of Economic Development and Socio-Cultural Integration in Ethiopia
}

\author{
Befikadu Melesse Taye \\ Department of Geography and Environmental Studies; CSSH, Wolkite University; Ethiopia
}

\begin{abstract}
Coffee is one of the most important agriculture commodities in the world. Ethiopia had been the origin of coffee, because coffee plant was initially found and cultivated in the Kafa province, colonized the world with its natural significance. Globally, coffee plays a significant economic role and serves as a major source of foreign earnings in many producing countries. The importance of coffee is embedded within the growing culture of attraction to the socio-economic significance intrinsic to it. Despite the wild perceptions many agree that coffee has less support to its homeland opposite to its global scenario. Most International reports confirms that the performance of coffee sector in home land has got insignificant, but with better attributes for prosperity with undiscovered reasons. Therefore, this paper aimed to see the role of coffee as driver of economic development and socio-cultural integration in Ethiopia. Archival documents were collected from different national and international reports, research findings and other relevant statistics were used to triangulate and cover the gaps. For collected data mixed data analysis methods were employed, where by after detail description of the data conclusions were made and targeted recommendations were forwarded as well. The study confirmed that even though it was/is economically the leading agricultural commodity, due to low production and productivity in relation to traditional agricultural practice, coffee didn't boosted the national economy of the country as it does in other producing countries. Ironic to this, coffee nationally come up with livelihood base of coffee dependent peoples, served as media of local communication and socio-cultural integration, the only commodity commonly consumed and gathered in ceremony throughout the country in particular and in the spoken by the same sound (word) in the world. Therefore, in order to balance the socio-cultural value of coffee at hand with the economic one all effort on harnessing the prevailing potential of increased production and quality of coffee, working in the value chain - winning uniqueness through branding as land of origin and working on institutional competency and quality delivery was highly recommended.
\end{abstract}

Keywords: Coffee; Economic Development, Socio-cultural Integration; Ethiopia

DOI: $10.7176 / \mathrm{DCS} / 10-5-02$

Publication date:May $31^{\text {st }} 2020$

\section{Introduction}

Coffee is one of the most important agriculture commodities in the world. Ethiopia had been the origin of coffee because coffee plant was initially found and cultivated in the Kafa province (Asrat et al, 2015), plays a pivotal role in the socio-economy of the country (Amamo, 2014).

Globally, coffee plays a significant economic role and serves as a major source of foreign earnings in many producing countries (Bramel et al, 2016). Produced in about 80 countries, an estimated 125 million people in Latin America, Africa and Asia depend on it for their livelihoods (Bramel et al, 2016). The importance of coffee is embedded within the growing culture of attraction to the socio-economic significance intrinsic to it (Tadesse et al, 2013). Nowadays coffee is among the few internationally traded important agricultural commodities (Kew, 2017). Coffee is primarily produced by 50 developing countries and mainly consumed by 20 developed nations (Bramel et al, 2016). Prominently coffee is believed as a non-seductive drink socializing relationship. It is also regarded as an enlightenment of moments of every-day. Coffee as a living crop from the plant kingdom controversially possesses widely contemplated legends associated with place of origin, identification, ceremony, trade, taxation and others (Grotz, 2013). Despite the high disparities of flavor preferences, influenced by cultural and historic exposure, coffee is a persistent power of attractions for progressively growing number of consumers and producers across the continents- knowing no border.

Over the past 50 years, coffee production has achieved a continuous growth (Bramel et al, 2016). Virtually the number of consumers and volume of consumption has exhibited growth (Grotz, 2013) (ICO, 2017). The average annual growth rate for consumption by all importing countries for the period 1990 to 2012 was $1.5 \%$ compared to $1.7 \%$ for the period 1964 to 1989 (ICC, 2014). Currently the annual trade volume of coffee reached 8.7 metric ton (FAO 2011). Total consumption in importing countries in 2012 compared with 1990 and 1964 was estimated 98.6, 70.4 and 47.5 million bags respectively (ICC, 2014). This accounts 15 billion dollar worth monetary value (Seith, 2014). The growth of coffee production is strongly fine-twined with the culture and the associated legends of origin, cultivation tradition and reflection. Its mysterious journey from Kafa to Yemen and then the seven seeds to Dutch is one historic pact that had given rise to trace the origin by the name- Coffee (Grotz, 2013). Except for the beginning, the end is in pursuit - with lateral extension. 


\section{The Statement of the Problem}

The history of coffee in particular and coffee production and trade portrayed this fact. The last few years only the daily coffee cup consumed has increased from 1.6 billion to 2.25 billion cups (Seith, 2014). Eventually it indicates the prevailing progressive rise in demand - supply - chain and the inevitable increase on production volume. This dynamics thence will become repository in the globalization of coffee culture (Bramel et al, 2016). The division of role between producers, traders, exporters, transporters, roasters, tasters, packers, distributors, supermarkets, coffee houses, baristas, researchers, conservationists, economists etc and the prevailing bilateral and collective interdependence would be viewable as an important connectivity trait.

Coffee trade has progressively developed marks and standards over time as responsive to emerging consumer choices. The advancement of consumer preferences and technologies reckon standardizing coffee to various attributes. Largely the attributes are differentiated in many ways like shape, type of flavor and production system as well as place of origin. The current global market identifies coffee mainly by place of origin like Brazil coffee, Colombian coffee, Vietnam coffee, Ethiopian coffee, Kenyan coffee etc. This identification perhaps, with time, has further become localized to specific flavor linked supply sources such as Yirgachefe coffee, Sidama coffee, Geisha coffee etc. Even some like Ethiopian coffee in general and Yirgachefe coffee in particular emerged to serve as a bench-mark or reference for fine Arabica Coffee. This generally indicates the variance of consumer preference and suppliers diversification from roasting style- to place of origin and now to distinct flavor. And slowly consumers are becoming closely acquainted to production area, production ethics and to the producers.

In the course of coffee trade the notion about the magical plant, beyond the grounded bean, is very essential, but seems overlooked by the global community. Therefore, the aim of this paper is exploring the role of coffee as a driver of economic development and socio-cultural integration in Ethiopia.

Specific objectives:

Exploring and examining the economic imperatives of coffee in the study area;

Exploring the status of socio-cultural status of coffee in Kafa zone;

Coffee prospects as key issues in the home land of coffee.

\section{Materials and Methods}

The study used secondary data collected from different documents, reports and websites archived on coffee settings in Ethiopian context. Almost all the documents used were recent. After collecting the relevant data from relevant sources data analysis had its way. The data analysis techniques used descriptive (more qualitative) in nature. Most qualitative data with their intrinsic quality analyzed with explanations and the quantitative data comparatively analyzed and described in detail.

\section{Coffee: the Gift of Ethiopia to the World!}

Coffee belongs to the earth's plant community in the family of Rubiaceae. It belongs to one of the largest tropical plant category. Rubacie is a family in the plant kingdom that constitutes around 125 species (Bramel et al, 2016). Ironic enough only $1.6 \%$ of its family members are edible. Literally Coffee arabica and Coffee Robusta are the only two family members that serve the world. At global scale, the role of Coffee arabica accounts around $70 \%$ of production and market (Feyera et al, 2013). If we try to zoom-in, the aspect uncovers the credit of Africa as the main source of these magical plant species. Coffee Robusta is believed to originate in west-Africa as Ethiopia is the birthplace of Arabica Coffee. Despite the wild perceptions many agree the word coffee is derived from the name Kafa, a place in Africa, that was resided by the then Kafa Kingdome a place of origin in the southern nation, nationalities and people's regional state of Ethiopia (Birhanu, 2014). Coffee arabica hence is an African plant family residing in Ethiopia born in Kafa and named after its birthplace- Coffee (Grotz, 2013). In firm description, Coffee arabica is an Ethiopian that possesses an Ethiopian name - an African too ( (Birhanu, 2014). Though ignored and often coated with myths and hoax, this is very important. It is crux of the matter in the coffee production industry. It helps the global coffee community to trace and commemorate as Ethiopian treasure gifted freely to the world. The importance of tracing the origin is pretty crucial for the satisfaction of contemporary as well as the eventual consumer preferences, which is diverse, and to respond fast to the emerging challenges. Prominently ensure persistent production and supply from the reserve.

The catastrophe is not illusion rather eminent. In the past, 1970s, during the infestation of coffee berry disease (CBD) the global Arabica Coffee cultivars were in the verge of total extinction. Currently leaf rust is a production fear-factor in and around Latin America, Asia, Africa and Scandinavian countries - in all Arabica Coffee producing areas (Feyera et al, 2013). Economic recession and extinction were fear factors. The fast response of CBD was obtained from the wild relatives through selection and breading. It rescued the coffee industry, world economy and livelihood of poor producers. Down the decades, many CBD resistant varieties have been introduced - thanks to research and science. Perhaps the credit would extend to the rural community who cared and maintained the natural habitat. We all learned that the past time was relatively good in this respect. Rural Africans in general and Ethiopians in particular were rich in culture that kept them wise. They had rich moral elements that are ethically 
right. Perhaps they were blessed with plenty. There was less pressure on their abundant resources and their daily life was stress free. This reality had harbored certainty era. That was the good time where the needs and livelihood activities of Ethiopians were just for subsistence. The problems were bearable at individual, local and community level. With time lapse, however, things become changed in the course of intensified and multiplied challenges. Needs and obligations reproduced. Indigenous knowledge dimensioning as individualism sprouts fast overshadowing the past prestige. Since then, down the decades, there have been many changes that have exhibited persistent dwindling of the invaluable resource bases as opposed to the geometrical increase of population number, demand magnitude and catastrophic incidents.

The sum outcome became degradation of soil, high water stress, micro-climate hostility and increase insecurity. Insecurity that can be assessed in terms of using natural resources, insecurity in sustaining family-hood, insecurity at the scale of neighborhood, locality and nationwide.

At a general outlook demand in coffee supply at a global scale is progressively increasing. It requires increasing production and productivity. Global challenges are also equally excelling in an unprecedented speed. The coffee sector appeals rescue mechanism fast and effective. Survival of the fittest in the natural habitat, at its ideal location is important. It is there very long time response and adaptation has been naturally experimented and biologically undergone adaptation engineering responsive to variables that does not suit to the handful commercial relatives, which are very sensitive. Here the real essence of the so called "origin" becomes apparent and imperative. Ethiopia appropriating wide diversity in coffee variety, production system, climatic condition and rich culture in general and Kafa as center of origin and diversity of Arabica Coffee, has the best qualities with low caffeine content and fine aroma (Kassahun et al, 2013), UNESCO (2010), may need attention for the satisfaction of additional supply, with basket full of flavor choices while serving defense mechanism for the uncertainties sprouting out of changing challenges. Ethiopia needs to focus more now. If Ethiopians are good, the land is good, then blessed be the world-Why? Because it is the land of origin pioneer life experience as well as persistent endurance in broader engagement unto global scale indeed. Ethiopia! Land of origin- important life reference on human nature, human culture, ancient modernization had begun and evolved there. For coffee still has plenty, to tell, offer and share: notwithstanding co-benefit indeed.

\section{Economic Imperatives of Coffee}

\subsection{Coffee production and marketing}

Coffee is called 'Bunna' (boo-na) in Ethiopia, but as the plant spread out in the area as far as the Arabian peninsula across the Red Sea people referred to it as Kafa or Coffee for the region it came from. The reason for its early spread was as an edible product mostly for the caffeine (EED, 2011).

Coffee production is vital to the Ethiopian economy with about 15 million people directly or indirectly deriving their livelihoods from it. It is mainly produced in the southwestern and southeastern parts of the country (Abu Tefera and Teddy Tefera, 2014).

Ethiopia is currently the top African coffee exporter and ranked sixth in the global market. Ethiopia exported 170,888 tons of coffee and earned \$525.2 million during June/July 2007/08 period compared with 176,390 tons worth $\$ 424.2$ million in 2006/07 (Chemonics, 2010). Between the year 2013 to 2016 Ethiopia's average annual coffee production reached from 391,620ton to 404,490 ton with 5.75\% increase in 2016 (ICO, 2017). This accounts $4 \%$ of share of the country's Gross Domestic Product (GDP) and 10\% of agricultural production. It also represents $41 \%$ and $4.5 \%$ coffee production of Africa and the world in 2016 (ICO, 2017). From 2009/10 to 2014/15 coffee fetched on average 613.92 million dollars annual export earnings. It accounts $37.35 \%$ of average earning of agricultural products and $28.92 \%$ of the total export earnings of the country. During good years like in 2010/11 it generated annual revenue equals over 841.7 million dollars and accounts about $30 \%$ and $41.76 \%$ earning share from total export and export of agricultural commodities respectively (JARC, 2017). With this share coffee continues as the leading export commodity of Ethiopia.

Table: 1 Total production of Coffee (In thousand $60 \mathrm{~kg}$ bags)

\begin{tabular}{|l|c|c|c|c|c|}
\hline Crop Year & 2013 & 2014 & 2015 & 2016 & $\%$ change 2015-16 \\
\hline Ethiopia & 6,527 & 6,625 & 6,714 & 7,100 & $5.7 \%$ \\
\hline Africa & 16,244 & 16,014 & 16,349 & 17,208 & $5.3 \%$ \\
\hline World & 152,232 & 149,053 & 152,253 & 157,437 & $3.4 \%$ \\
\hline
\end{tabular}

Source: (ICO, 2017) Available on www.ico.org/trade_statistics.asp

Coffee production constitutes four primary systems: forest coffee, semi-forest coffee, garden coffee and plantation coffee production systems. The variability of the production system is attributed to ecological suitability, location diversity and many coffee production traditions across the social setup. Hence, the source of Ethiopian coffee is diverse (JARC, 2017). This gives rise to produce wide coffee varieties attributing special taste, aroma and flavor. The first two production systems are dependent on the natural occurrence. They have special behavior that needs little effort other than minor slashing type of management and harvesting. Plantation coffee is based on capital and labor intensive production system. It combines technology, technical knowledge, input and capital 
investment. Except for few, the then state farms of the x-government, 45,000ha plantation coffee has been established within the last two decades. The other coffee production system, garden, is the second largest in area coverage. This farming system is sub-divided into native tree, agro-forestry, enset and artificial shed based garden production. The secrete behind the wide range of variation in aroma, taste and flavor emanates from this positively responsive traits. Though, some identification is achieved for Sidama, Yirgachefe, Kochere, Harar, Limu ete. It is a job to do in bringing such localized identification for many localities of Ethiopian coffee in the coming few years.

Table 2: Information on the four Coffee Production Systems and Annual Yield estimation

\begin{tabular}{|c|c|c|c|c|c|}
\hline S.N & Production system & Area in $\mathrm{Ha}$ & $\begin{array}{l}\text { Area } \\
\text { in } \%\end{array}$ & $\begin{array}{ll}\text { Average } & \text { Productivity } \\
\text { Ton/ha } & \end{array}$ & $\begin{array}{l}\text { Estimated annual } \\
\text { product (tons) }\end{array}$ \\
\hline 1 & Forest coffee & 175,000 & 19 & 0.25 & 43,750 \\
\hline 2 & Semi-forest coffee & 400,000 & 43.5 & 0.5 & 200,000 \\
\hline 3 & Garden & 300,000 & 32.6 & 0.6 & 180,000 \\
\hline 4 & Plantation & 45,000 & 4.9 & 1.0 & 45,000 \\
\hline & Total & 920,000 & 100 & 0.47 & 468,750 \\
\hline
\end{tabular}

Source: (MoANR, 2017): Annual review report

Ethiopia has long history of coffee production and export (Bart et al, 2014). Despite this Ethiopia still has not met the global competency it deserves to arrive at. With huge production potential, ecological advantage, diversity of cultivars, indigenous knowledge and conducive policy and structural facilities both productivity and yearly production volume exhibits incompatibility to the context (Kotecha, 2007). Internationally Ethiopian Coffee is considered fine coffee (Kassahun et al, 2013); (Seith, 2014). Particularly some of the well known Ethiopia's brands like Yirgachefe, Sidama, Limu and Harar have secured export market. Whereas other areas like Kafa, BenchManji, Sheka, Illu-Ababora, Gedio, Hageremariam etc having uniqueness have not yet got popularity and brand. And yet are enjoying premium price in niche markets. But for big volume support for branding and promotion should undone assignment down the road. Garden coffee as a good land management practice and adaptation strategy is the undone assignment. It would help to increase the total coffee production area of the country. There are pragmatic experiences in the southwest in general and Kafa zone in particular. In Kafa the coffee expansion program run (with interruption) since 2010 has created over 100,000ha of garden coffee and productivity enhancement to an average of 0.95 ton per hectare (KZANRD, 2017)- almost similar to the results achieved in research station JARC, 2016). Surprisingly enough field observation (on National coffee day) in Bita woreda and Chena woreda confirmed that model farmers already hit the productivity ceiling and enjoyed the outcome. This progress together with the achievement of engaging over 100 investors in plantation farming brought visible transformations in the zone. Learning from models and learning from laggards converting into knowledge, generating improvement ideas, creating package options, mobilizing resources may make Kafa zone model development region. Particularly following the functional zoning and spatial development planning certainly, model a balanced relationship between nature conservation and economic development. Coffee producing areas may need information system to support, facilitate and monitor the production of high volume and quality cultivars. If shared responsibility and concerted intervention turn into, perhaps pragmatically proven in its success, practice the lesson-learning brings multiplication effect. Thus in near future coffee will reach to its peak and continue to be the leading and paying important cash crop of Ethiopia, Africa and consumer countries.

\subsection{Domestic consumption of Coffee}

Even though coffee as important cash crop of Ethiopia generates considerable revenue there exhibits huge share left out for domestic consumption. In between 2010/2011 - 2014/15 from the total national coffee production of $439,836.4$ ton, only $187,866.24$ ton, $43.5 \%$, was exported (ICO, 2017). The remaining 251,970.16 ton, $56.5 \%$ was kept for domestic consumption. This reminds a simple effort coupled with good set of information system can redirect additional proportion of coffee from domestic consumption into export and significantly soar the earning of foreign currency.

Table: 3 Total coffee production, export and domestic consumption (2011-2015).

\begin{tabular}{|c|c|c|c|c|c|}
\hline \multirow{2}{*}{ Year } & \multirow{2}{*}{ Production } & \multicolumn{2}{l|}{ Exported Coffee } & \multicolumn{2}{l|}{ Domestic Consumption } \\
\cline { 3 - 6 } & Volume (ton) & \% Share & Volume (ton) & \% Share \\
\hline $2010 / 11$ & 363,232 & $196,119.22$ & 54.0 & $167,112.78$ & 46.0 \\
\hline $2011 / 12$ & 498,767 & $169,392.13$ & 34.0 & $329,374.87$ & 66.0 \\
\hline $2012 / 13$ & 486,685 & $199,103.58$ & 40.9 & $287,581.42$ & 59.1 \\
\hline $2013 / 14$ & 400,852 & $190,875.93$ & 47.6 & $209,976.07$ & 52.4 \\
\hline $2014 / 15$ & 449,646 & $183,840.36$ & 40.9 & $265,805.64$ & 59.1 \\
\hline Average & $\mathbf{4 3 9 , 8 3 6 . 4 0}$ & $\mathbf{1 8 7 , 8 6 6 . 2 4}$ & $\mathbf{4 3 . 5}$ & $\mathbf{2 5 1 , 9 7 0 . 1 6}$ & $\mathbf{5 6 . 5}$ \\
\hline
\end{tabular}

Source: (ICO, 2017)Available on www.ico.org/trade_statistics.asp

Except the magnitude, no clear information on domestic consumption (Kassahun et al, 2013). There is no 
available information to differentiate and disaggregate domestic consumption by type. However some preliminary signs show the broadness. It encompasses owners such as coffee shops, roadside coffee sellers, groceries, hotels etc. Domestic consumption increase emanates either from quality problem that is rejected from export or unwillingness to supply for export. The later includes "illegal marketing" and small producers' decision to keep for own consumption. Garden coffee includes few coffee stands in the backyard of poor farms. For statistics reason such small producers are often included in the reporting. The annual products maybe few kilos of red-cherries that they decide to consume than sale. This will sometimes combine with low market prices force such producers to avoid supply. In most cases low selling price set below local price push some greedy or nervous merchants to adulterate and affect export volume. The growing coffee shops, coffee vendors and ecotourism promoters may trap foreign currency from the service to tourists as well as UN staff and diplomatic community. However this requires systematic study.

Coffee also provides employment and livelihood support for over 15 million people that are directly or indirectly dependent (Abu Tefera and Teddy Tefera, 2014). Around 2 million smallholder growers also depend on coffee for their income and livelihood. Extension advices and control mechanisms contributed in shaping the behavior of smallholder- growers towards good management and coffee quality maintenance. These management activities often require additional labor for seasonal actions like clearing, picking, drying etc. Because of this many growers start hiring laborers. It means additional job opportunity is created. This requires study. There are many practical evidences in Kafa, Sheka, Bench Maji zones that small farm owners hiring local laborers for picking, clearing, compost application, etc. Roadside coffee sellers with their supporters also get benefit from income. Though not significantly strong pointers, bamboo cup makers etc are now getting connected in the business using their traditional skill. The southwest has many experiences that deserve assessment; Ethiopia is origin and center of diversity of Arabica Coffee (UNESCO, 2010; (Grotz, 2013). This gave rise to the possibility of diverse production systems notably forest, semi-forest, garden and plantation coffee. Garden coffee reveals some sort of variation in terms of upper-story set up Particularly garden coffee includes coffee under remnant tree, coffee under shed tree, coffee under Enset plant, coffee as multi-story agro-forestry system and to lesser extent coffee in open backyard. These serve soil and water conservation. The sheds protect direct sun heating and reduce transpiration, they contribute nutrient recycling from decomposition of foliage and other shed biomass protects soil erosion, vegetation's improve humidity and microclimate. It harbors biodiversity especially birds and other small living organisms (Aaron, D. et al, 2013). This avoids conservation and resettlement cost directing spending in other sectors (Tadesse et al, 2013). Institutions of smallholder producers like cooperative unions established for special type of coffee like KFCFU, BFCFU or OFCU attract different buyers situated in different countries and let establish long-term agreement for selling from a particular production system for certain premium price (Chemonics, 2010). As the diversity still can be differentiable to the level of localities the opportunity and possibility rather demand to tap as deserving as the uniqueness the effort put from the traditional knowledge into the pleasure of end consumers in developed countries. For example Farmers produce forest coffee and also garden coffee. Though not worked out the two production systems constitute their own uniqueness. Coffee is also produced from an altitude gradient ranging from 1000masl to 2000masl in the garden and from the forest. Mini investors of farm size between 1 ha to 100 ha will have particular uniqueness that can meet particular consumer preferences.

Provided a wide notion of the association of the name coffee with Kafa it is an appetizer to promote. Especially the last 15 years Kafa had established different coffee production systems (KZANRD, 2017). If worked effectively this would add one additional Ethiopian brand with historic resume.

\subsection{Coffee Tourism}

The Kafa Biosphere Reserve is Ethiopia's first biosphere reserve and the first coffee biosphere reserve of the world, which can be recognized as a worldwide attraction for coffee consumers and eco-tourists (NABU, 2012). Coffee tourism could be a new socio-economic track for Ethiopia. The country practice different production systems. All systems do have their uniqueness. Traditional knowledge under garden coffee, forest coffee and semi-forest coffee would be likable option to satisfy and keep tourists (David Boansi and Christian Crentsil, 2013). There are some experimental trials in Kafa, Sheka and Yayu biosphere reserves (NABU, 2015). Tourists can be offered various tourism packages such as visit to original place with legend, coffee trekking, experiencing coffee picking, coffee flower visit etc can be options to attract both domestic and international tourists. It is a possible economic sector for southwest and southeast forested localities. It perhaps is unbeaten potential.

Coffee culture can be another potential for tourism development. There is diversity of cultures in the country, identification, promotion and providing support can create variety of offers. Utensil making and sell for tourism purpose is a potential as well.

Conference tourism can be other economic premises based economic opportunity that could definitely bring Ethiopia's diverse culture and social connectedness to refreshment and revival (NABU, 2013). It may create a new era for demonstrating the transformation of diversity of (coffee) nature into the national culture (lifestyle and 
production) that lately spread across the world with economic flagship.

Globally coffee diversity outside Ethiopia is narrow. It is believed to be less than $1 \%$ of the overall diversity in the world (Seith, 2014). Ethiopia constitutes the world coffee biodiversity greater than all the other coffee growing countries do have all together. To be origin and center of diversity is a unique blessing for plants like coffee that are very vulnerable to climate change effects and attack by diseases, pest, fungus and worms. In Ethiopia coffee occurs in wide range of ecological conditions. The issue to be origin in the natural environment means there is successful adaption ensured through long time natural rule called 'survival of the fittest'. Currently the role of research in the coffee industry is indispensably critical. Especially the imminent effect of climate change and associated pathogenic challenges has begun putting pressure on the pursuance of coffee production. The varieties that are narrow in variability are easily exposed to inability to cope. Wild coffee hence is believed to be reliable sources that offer adaptation alternative by making selection from the natural forests where it exists (Franz et al, 2013).The global economic value of the wild coffee for research was estimated to be $0.5-1.5$ billion dollars (Franz et al, 2013).

In the 1970s the coffee berry disease devastated with huge cost implication on the global coffee producing countries including Ethiopia. In the decade the annual global green coffee production has reached 8.7 billion metric ton. Neither the major producers nor the consumers accept quantity and quality compromise. Some producer countries are suffering due to narrow diversity of land race. Setting advanced system the country can benefit from access- and- benefit-sharing scheme. Defending bio-piracy is equally crucial. It is not worth mentioning the mistake with Geisha coffee.

Also coffee is sold in the form of seed. Even though there is no consolidated data, the last two decades have been the period of new coffee farm establishment. Recent report indicates that a total of net land area covered by coffee grew by 393,709 ha from 2004 to 2016 (JARC, 2017). The average annual new coffee production land area increase had been 30,285 ha. This obviously had been a daunting responsibility. Hence it would be very thoughtful to articulate coffee reserve for seed. Especially the current uncertain environmental dynamism makes this a very critical matter. Preparedness for unexpected challenge through creating reserve area for any unpredictable calamities is pivotal. Emergency seed will provide short-term answer. It fills time gap. It narrows production gap. This provided security and prompt continuation of production for coffee farmers. The case of Kafa zone can be very good example. The zone has continually supplied coffee seed at an average yearly amount up to 500 quintals from garden coffee to different zones and special woredas of SNNPR during the last few years (KZANRD, 2017). Adapting climate change with a strategy of geographic shift is being exercised and its importance to maintain security and constant production does have economic benefit. In the future it is possible to measure the economic value of this exchange at the scale of export maintenance and security. If a very systematic monitoring and early warning system, by research and education institutions, is in-placed in the main production areas of the country it is possible to forecast (GTZ, 2008). By using such information system, preparedness and action with the right seed supports replacement mechanism before complete wiping occur. Seed in the cold house and in the farm hence become a benefit to continue coffee export at a predictable confidence limit and benefit producers by protecting the exposure to devastation.

\section{Socio-Cultural Significance of Coffee 4.1. Coffee Ceremony}

Coffee is deeply intertwined in the social, cultural and historic identity of Ethiopian (UNDP, 2012). The pride of belongingness to the origin of Coffee Arabica is a shared attitude. Ethiopians consider and certainly believe that coffee is prestigious resource the nation presented to the world (Bierber, 1920). Coffee ceremony is a passionate process where owners of a particular home prepare, invite and enjoy drinking. Down the century and across the nation coffee ceremony becomes an integral part of social and cultural life of people. An invitation for coffee ceremony is symbolic of friendship respect and hospitality. Performing the ceremony is almost obligatory in the presence of a visitor, whatever the time of day.

For many rural and pre-urban Ethiopians making and drinking morning and evening coffee has been a custom routinely repeated every day. It is part of daily life that develops relationships. It constitutes regular conversation platform. It is a bell awakening sleepy ones. The starters always are women who repeat door opening for coffee preparation in love. Women are masters of coffee ceremony. They well know the positive appreciation to begin the day with sensation. For those family members it is always a pleasant memory to commemorate what awakes them every morning.

Flaming fire, coffee roasting and coffee pounding have rhythm that is like alarm to awaken family members. The polite request of fire sharing from neighborhood, the 'shaar-shaar' sound of roasting, the sound of ka..ka from the fire silently whisper to the ones soul to be ready and get-off the bed. Unless situated too far or obscured by natural barriers neighbors notice the approaching door nock or call saying "hallo miss and mister, come and drink coffee!" or "coffee is served" - sharing the daily beginner - coffee. It continued as this for long being the beginner of daily life (Seith, 2014). Many neighbors, family and casual visitors will have memories to be driven 
back. Coffee before its economic championship was just integral part nature in the wilderness. Mankind transformed it into socialized culture - lifeblood that adhere and lubricate social relationship. The social relationship built has been transformed into the culture of generosity and pleasure. Lastly, freely transform to economic prosperity, perhaps more for others. The so-called coffee ceremony at present is a social coffee drinking practice acculturation across the country with large similarly. During old times economic greed had no place, coffee culture is additive to the natural gift- to the coffee itself.

In rural Kafa waking by coffee making sounds and smell from roasted aroma is the center of attraction. This spirit of coffee continues up to the end of the last round of the coffee -called Chambo in Kafa or Maktemiya or Baraka in other parts of the country is one lifestyle pact demonstrates shared value, hospitality and considerateness. Currently thanks for Ottoman Empire (Grotz, 2013) it is awarded with Goody name "Abol-Tona-Baraka" (Bierber, 1920). The last means praised. It seems an excuse for the myth coffee was translated to Khaha meaning devil. Irony by itself and uncovers the hoax about the origin.

In Ethiopia, neither the name nor rounds are devilish. It rather is excitement. In Kafa for example the sprit is considered to abide with sipping the last round, i.e., through drinking Chambo. The most important ritual element of this is avoiding sipping from Chambo was believed to encounter with curse all day long. Hence all remain seated until the master of the house blesses and the woman, architect of coffee making, being thanked by all. This is a love moment that all leave with cheer.

Apart to starting the day coffee serves to perform various social and ritual practices. It facilitates marriage. Neighborhood coffee sharing often serves an insurance of relationship that is often advanced by marriage bond. Though family marriage arrangement is abandoned still many rural parents propose a marriage for their children and suggest coffee invitation as a good opportunity to see or know the proposed lady. Coffee is comfort making social belongingness. It still holds the power of attraction - irrespective of acquaintance.

\subsection{Coffee for Conflict Resolution}

Coffee also maintains the role of conflict management and resolution. Primarily it puts pressure as societal norm not to get into confrontation. It forces neighborhood coffee sharers to present complaints to elderly or other neighbor rather than confrontation (EED, 2011). If two neighbors who sharing neighborhood coffee are drinking get into some kind of confrontation and violence, it brings critique and regret from other neighbors and mostly by the whole villagers. In such conditions, elderly neighbors arrange mediation and reconciliation practices. Coffee spirit become coercing ego forcing the subjects give-up their anger and grievances to come forward and embraces each other and end the conflict. There coffee the credit as master piece calming their ego. Regrettably, this seems no more respected. Nevertheless, since valuable it should work. We must fix it. Why, because it serves us all. The coffee spirit politely asks.

\subsection{Coffee as social media}

With Ethiopian being not only a major producer and exporter of coffee, but as well the highest consumer thereof in Africa. (David Boansi and Christian Crentsil, 2013). Coffee has been a social media to exchange information, skill, get support, advice or even medical treatment from traditional healers (EED, 2011). Free discussion and consultation seems developed from coffee culture. Coffee stimulates conversation. The long acquaintance to each other through neighborhood coffee ceremony participation, discussion on issues is open even for kids. Unless the topic is highly sensitive or not relevant for kids and women are equally represented without the usual segregation. Currently, coffee plays its crucial role as media for development and critical affairs - like mainstreaming HIV through "coffee ceremony" is an additive while most of us abandoning our past (NABU, 2011).

The three round of coffee boiling in Kafa is linked with two interlinked reasons. Always women roast more coffee and keep some roasted and pounded coffee with them. Coffee created considerateness. The reason behind is they expect casual arrivers who should be served. The second is creating long discussion moment by adding part of reserve into the second round pot. Particularly the third round is associated with the good spirit- associated with some-sort of rite. It teaches patience, obedience and social respect irrespective of hurriedness.

The culture of receptiveness in coffee service is a very important feature that is relevant for the contemporary situation. Coffee invitation or show-up do not have conditionality. Strangers can easily join and ask for support or can connect to areas they have no someone to talk to.

In the southwest many poor people benefit to quench seasonal hunger by participating in the neighborhood coffee drinking. Coffee always is accompanied with some grains, kocho or taro served with coffee to neighbors. This extends its value for hungry, strangers and poor. Many experts that travel for fieldwork made clever use of this culture for getting more to eat, more to know, more to influence through informal discussion.

\subsection{Coffee in Homemade Medication}

Coffee serves for homemade medication. Many rural house wives have indigenous knowledge in homemade medication. For instance, 'Chamo' prepared from fresh coffee buds or young leaves; traditionally prepared and 
consumed in Southwest Ethiopia (Tadesse et al, 2013) believed to prevent from malaria. Obtaining roasted coffee flour and honey in the rural women's belonging will not be a surprise. Their pharmaceutical belonging is always stocked. Most importantly, this knowledge and treatment is transferable. Through this it pursued till today. In general a coffee drinking is not just a ceremony the first transformation of nature to social relation that become binding as well as symbolic culture through not only repeating but also utilizing the positive elements embedded beyond sipping it. In the former time it is a true source of information exchange, digestion of pressing issues, passing decisions, shaping behavior by anchoring social coercions that influence belongingness attitude, confidence and interdependency in the form of unity.

\subsection{Coffee for Unity}

In the cities and towns, people are used to invite for coffee - "Let's drink coffee" (Befikadu, 2018). Particularly if the invitation is into the invitee house it might mean invitation for food, drink or even wedding. It is a comfort zone for invitees to show-up without embarrassment of complex. Currently small coffee venders and coffee houses seem determined to keep the identity of coffee.

The traditional utensils also tell many stories. Before the china coffee pots and cups there were the first pots and cups. These are adapted across the country and created diverse style. For example the Kafa pot that is without separate outlet reminds the use of butter in the ancient time so as to share equal portion of butter for attendants. This is a sign of equal respect to guests, neighbors and all family members. The cup made of bamboo is another surprise for its cool outside while the inner coffee keeps boiling. Clay cup similar to the present imported cup is a sign of nationally shared value in the coffee culture. Overtime there are many location specific cultures and utensils across the country that would better connect each other in a constructive way. As coffee is a love it is the right area to begin cultural exchange - intercultural appreciation and acquaintance on similarly and differences (Kotecha, 2007). Coffee has much to tell how the past inter-societal relationship was strengthened by learning from each other.

\subsection{Coffee for Partnership}

Coffee also has the potential for transformation. Many entrepreneurs, business partners use coffee as the power of motivation for generating their thoughts, initiated venture and forged binding force to transform into actions (Seith, 2014). Coffee is an ego fostering meditation at schools helping learning and reading. Many students use coffee to stay alert and read long until late evening without losing concentration.

The movement of coffee preparation is also a soothing wakening alert taken by resonant musical instrument of roasting and pounding and inhaled from the morning houseful aroma that is accustomed lifelong (Grotz, 2013). The mood always is concurred with the eager to sip a cup of coffee. Waiting for coffee all the other family members start talking about the day ahead. Even though sometimes scattered the aroma and pounding sound is not limited for the family but also for neighborhood. Neighbors make their preparation and join opening broader discussion topic. The early coffee growing areas of the country like Oromia, SNNPR and others coffee is a lead and concluder of daily life. It starts the day of family. Weather the family is at house or in the field; he will be visited with morning coffee. Coffee is a power that starts creating and maintaining relationships. Neighborhood invitation of coffee has never avoided interchange among for the day.

\section{Conclusions}

Ethiopia is the past-present-and future home of Coffee Arabica (Grotz, 2013). It is originated in Kafa (Bierber, 1920) - the land of Ethiopia (Birhanu, 2014) Spread and connected people. At present the production potential, the possession of wide diversity excelling from all global countries makes the possibility to achieve the leadership in quality coffee production and export. Perhaps coffee can generate high foreign earnings.

In the future when the planet suffers climate change induced cultivar extinction, the world will turn its face to the most coffee diverse country- to our Ethiopia! Ethiopia would be the center of answers for all coffee variety needs of the global community. Perhaps the country is faced with challenges as well. Deforestation and soil degradation, climate change, bottle necks of research and learning, lack of focus and priority to coffee sector, etc are outstanding (JARC, 2017).

\section{Recommendations}

For better sustainability of coffee sector balancing our common present use with the future needs - with no discount! What we call sustainability through optimization of our common needs- the needs of meeting the present without compromising the future belonging to our others- next generation! What do we have? Our outlooks and visions - perhaps that should be based on practical, simple and reachable goals - in the near future of our present coffee.

To move forward it needs a starter. The starter that is easy to initiate thinking, planning and action. That perhaps mobilizes all actors - no entity could be left out as all are important powerhouse to drive both forward and 
inertia of hindrance. In this respect the following areas are put as starters:

- Effort on harnessing the prevailing potential of increased production and quality of coffee;

- Devise mechanism to cope with the eminent challenges: including climate change, deforestation, photogenic problems, environmental degradation etc.;

- Institutional competency and quality delivery - knowledge acquisition from research, learning and extension institutions: "enduring the sting to enjoy the honey";

- $\quad$ Putting the last first - community role and protection for excelling betterment not worseness;

- Identification and global competitiveness -working in the value chain - winning uniqueness through branding;

- Customizing the customs and culture in excelling harmonic diversity and connectedness via the coffeeculture.

\section{References}

NABU. (2013, March). "Sustaining Life: the Cloud Forests of Kafa”, Marketing Concept for the Kafa Biosphere Reserve, Ethiopia Augustin Berghöfer | Christiane Stadler | Georgina Langdale, 15.

Abu Tefera and Teddy Tefera. (2014, May 13). Global Agriculture Information Network: REPORT CONTAINS ASSESSMENTS OF COMMODITY AND TRADE ISSUES MADE BY USDA STAFF AND NOT NECESSARILY STATEMENTS OF OFFICIAL U.S. GOVERNMENT POLICY. USDA Foreign Agricultural Service.

Amamo, A. A. (2014). Coffee Production and Marketing in Ethiopia . European Journal of Business and Management, 109

Asrat et al. (2015). WET COFFEE PROCESSING WASTE MANAGEMENT PRACTICE IN ETHIOPIA; ASIAN JOURNAL OF SCIENCE AND TECHNOLOGY, 1467.

Bart et al. (2014, June). Structure and performance of Ethiopia's coffee export sector . International Food Policy Research Institute.

Befikadu. (2018). Forest Coffee Production in Ethiopia: The Case of Gimbo District,Kaffa Zone, Southwest Ethiopia. Journal of Natural Sciences Research, 44.

Bierber. (1920). An Ancient Cushiotic Tribe in Inner Africa: Records of Land and People, Tradition and Customes of the Kefficho or Gonga and Empire of Kafa. Aschendorffsche, Minister (Volume One).

Birhanu. (2014). Mythological and Historical Background of Coffee, . Addis Ababa, Ethiopia: Addis Ababa University.

Bramel et al. (2016). Global conservation Strategy for Coffee Genetic Resources,. Crop Trust.

Chemonics. (2010, June 18). ETHIOPIA COFFEE INDUSTRY VALUE CHAIN ANALYSIS: PROFILING THE ACTORS, THEIR INTERACTIONS, COSTS, CONSTRAINTS AND OPPORTUNITIES. KENYA COFFEE INDUSTRY VALUE CHAIN ANALYSIS .

David Boansi and Christian Crentsil. (2013, August 4). Competitiveness and determinants of coffee exports, producer price and production for Ethiopia. Corvinus University of Budapest, Hungary, University of Reading, UK, p. 3.

EED. (2011, March 08). COFEE. Selamta, The In-Flight Magazine of ETHIOPIAN AIRLINES.

Feyera et al. (2013). Wild Coffee and Coffee forests in Ethiopia . Botanischer Garten und Botanisches Museum Berlin-Dahlem. Berlin.

Franz et al. (2013). The Economic Value of Wild Coffea Arabica as a genetic Resource. Botanischer Garten und Botanisches Museum Berlin-Dahlem. Berlin.

Grotz. (2013). Coffee- A Globall success. Berlin, Germany: Botanischer Garten and Bothanical Museum.

GTZ. (2008). GTZ. UNESCO Biosphere Reserves; A tool for conservation and development in Ethiopia, Stakeholders' Workshop on Legal Aspects .

ICC. (2014). International coffee council world coffee trade (1963 - 2013): A review of the markets, challenges and opportunities facing the sector.

ICO. (2017). International Coffee Organization:www.ico.org/trade_statistics.asp.

ICO. (2018). International Coffee Organization; Coffee Market price ends 2017.

JARC. (2017). ETHIOPIAN INSTITUTE OF AGRICULTURAL RESEARCH; NATIONAL COFFEE COMMODITY RESEARCH STRATEGY FIFTEEN YEARS (2016 - 2030). USID.

Kassahun et al. (2013). The Natural History of Coffea- What is Arabica Coffee? In Grotz, Kaffee.Ein globaler Erfolg: Coffee.A Global Success (p. 30).

Kew. (2017). Cofee Farming and Climate Change in Ethiopia: Impacts, Forecasts, Resilience and opportunities Summary Report. ECFF.

Kotecha, S. (2007, August 12). Arabicas from the Garden of Eden - COFFEA AETHIOPICA ; Arabicas from the Garden of Eden: Coffea Aethiopica - Speciality Coffee Association Europe . For SCAE (Speciality Coffee Association of Europe) magazine Café Europa . 
Kufa, T. (n.d.). Environmental Sustainability and Coffee Diversity in Africa; National Coffee, Tea \& Spices Crops Research Coordinator. Ethiopian Institute of Agricultural Research.

KZANRD. (2017). Kafa Zone Agriculture and Rural Development Department Annual Report. Unpublished.

MoANR. (2017). Annual report. Addis Ababa : Misntry of Agriculture and Natural Resources .

NABU. (2011). Protecting the Last Cloud Forests of Ethiopia; A project supporting the preservation of the wild coffee forests in Kafa Zone. Berlin, Germany, www.NABU.de: International Climate Initiative.

NABU. (2012). Kafa Biosphere Reserve, SNNPR, Ethiopia; Progress Report Brief (2010-2012).

NABU. (2015). KAFA Biosphere Reserve, Off the beaten track: Your Visitors' Guide: www.kafa-biosphere.com.

Seith. (2014). Bread wine chocolate: The Slow Loss of foods we Love, First edition Harper one. New York.

Tadesse et al. (2013). Coffee is the Ethiopia's Gift to the World. Botanischer Garten und Botanisches Museum Berlin-Dahlem. Berlin.

UNDP. (2012). United Nations Development Programme;Proposal for Coffee Platform in Ethiopia. 